\title{
Sleeping Habits and Nutritional State of Pre-schools
}

\author{
Haider JCMC ${ }^{1 *}$, Pellanda LC $^{\mathbf{2}}$ and Gonçalves JS ${ }^{\mathbf{3}}$ \\ ${ }^{1}$ Health School, Rio dos Sinos Valley Universe, São Leopoldo/RS-BR, Brazil \\ ${ }^{2}$ Rectory, Federal University of Health Sciences of Porto Alegre, Porto \\ Alegre/RS-BR, Brazil \\ ${ }^{3}$ University Foundation of Cardiology, IC/FUC - Porto Alegre/RS, Brazil \\ *Corresponding Author: Haider JCMC, Health School, Rio dos Sinos Valley \\ Universe, São Leopoldo/RS-BR, Brazil.
}

\author{
Received: October 05, 2021 \\ Published: October 08, 2021 \\ (C) All rights are reserved by Haider JCMC., \\ et al.
}

\begin{abstract}
Childhood obesity has reached epidemic proportions, generating several lines of research on the associated risk factors, and an issue currently addressed is defective and poor quality sleep in children. Studies show a positive relationship between defective sleep and childhood obesity. Objectives: To verify if the quality of sleep can affect the nutritional status of children aged 0 to 6 years. Methods: Cross-sectional study conducted in two cities in the state of Rio Grande do Sul/Brazil. The study was approved by the Research Ethics Committee (Protocol 4640/11). After signing the Free and Informed Consent Form (ICF), the parents received a questionnaire containing questions about life habits, together with the Food Frequency Questionnaire (FFQ), and also, for sleep assessment, the Sleep Quality Index of Pittsburg (PSQI-BR) adapted. Subsequently, an anthropometric assessment was performed. The analysis was performed using the SPSS version 18.0 statistical program. The prevalences are in the form of proportions with $95 \%$ confidence intervals. Results: The total sample of the study was 179 children. Of the total sample, $52 \%$ were female and $48 \%$ male. The average number of hours per night was 9.4 hours. The rate of overweight and obesity was $70 \%$. As for the quality of sleep, 7.3\% is classified as poor. Conclusion: The study verified whether the amount of hours of sleep in the sample appears to be insufficient for age, and may be related to the rate of overweight and obesity.
\end{abstract}

Keywords: Sleep; Nutritional Status; Child; Cardiovascular Risk Factor and Obesity

\section{Abbreviations}

ICF: Informed Consent Form; FFQ: Food Frequency Questionnaire; PSQI-BR: Pittsburg Sleep Quality Index; BMI: Body Mass Index

\section{Introduction}

It is worrying that childhood obesity increases in a decreasing way, and as it is already known, it determines several complications in childhood and adulthood [1]. The more intense and precocious obesity or overweight appears, the greater the risk of persistence and the more serious as associated comorbidities, such as metabolic, cardiovascular, pulmonary, orthopedic, psychological com- plications (due to social exclusion and exclusion) and some forms of cancer due to obesity in adulthood [2,3]. In the second stage of the Family Budget Survey conducted by the Brazilian Institute of Geography and Statistics in 2008-2009, overweight was found in $40.6 \%$ of the population, in the pediatric age group, other national studies show prevalence of overweight that vary between $10.8 \%$ to $33.8 \%$ in different regions [3]. Although changes in the basic balance between the amount of calories consumed and the energy spent are obviously responsible for the obesity pandemic, the knowledge of the underlying factors is incomplete [4,5]. Therefore, there was a significant development of several lines of research on 
the subject [6]. One of the factors that has been investigated is the sleep quality of children [7]. Studies obtained that short sleep during childhood brings a greater risk for the development of overweight or obesity and contributes to an increase in glucose levels $[8,9]$. Given these data, and the consequences of childhood obesity, this study will investigate sleep quality and nutritional status and if there is a relationship between them in preschool children in two cities in Rio Grande do Sul.

\section{Materials and Methods}

This is a cross-sectional study carried out with preschool children in the cities of Frederico Westphalen and Porto Alegre, both located in Rio Grande do Sul. The study was approved by the Research Ethics Committee - Protocol 4640/11. All parents and/or guardians of the children signed the Free and Informed Consent Term (ICF), an authorization request was also delivered to the institutions, where the data collection was carried out. For study participation criteria, children should be between 1 and 6 years old. In each city a private school was selected with the criterion that the number of students in the studied range are similar, close to the estimated sample calculation. Children under the age of one year and parents who did not sign the informed consent form were excluded. After consenting to participate, a questionnaire containing questions about physical activity, eating and living habits was given to the parents and/or guardians of the children, together with the Food Consumption Frequency Questionnaire - QFA. To assess sleep habits, the Pittsburg Sleep Quality Index (PSQI-BR) was used, which was adapted for this study according to the population studied, and the questionnaire used to assess sleep quality, was originally published by Buysse., et al. (1989) [11], including questions that in some cases have subdivisions, of up to ten subitems. This questionnaire is based on 7 evaluation components: 1 . subjective quality of sleep; 2 . it takes time to sleep; 3 . duration of sleep; 4. habitual sleep efficiency; 5 . sleep disorders; 6 . use of sleeping medications; and 7. daytime dysfunctions. Each component can vary from 0 to 3 points, with 0 indication of "very good" quality, 1 "good", 2 "bad" and 3 "very bad". The analysis of these 7 components results in an index (PSQI) that can vary from 0 to 21 points. After completing the questionnaires, anthropometric assessment of the children was carried out, using the measures of weight and height (according to each age group) to calculate the body mass index - BMI, through the curves of the World Health Organization according to the age groups, using the $\mathrm{Z}$ score $[12,13]$.
The analysis was performed using the SPSS version 18.0 statistical program. The prevalence's described in the form of proportions with respective $95 \%$ confidence intervals. Continuous variables described using means and standard deviations, or medians and interquartile ranges. The association between risk factors was assessed using the chi square test or Fisher's exact test. Differences between groups with and without risk factors were assessed using Student's t or Mann Whitney tests for continuous variables and chisquare test or Fisher's exact test for categorical variables.

\section{Results and Discussion}

This study consisted of a sample of 179 children, with 90 children from the city of Porto Alegre - RS and 89 children from the city of Frederico Westphalen - RS. In the total sample, 52\% of the owners are female and $48 \%$ male. The average age of the sample was 3 years. In the study there was a large percentage of children who were overweight $(70 \%)$, with $53.3 \%$ located in the city of Porto Alegre, and $16.8 \%$ in the city of Frederico Westphalen (Table 1).

It was found in this study that the average number of hours of sleep per night was 9.4 hours, with sleep quality being considered good in $92.7 \%$ and poor in $7.3 \%$. Poor sleep quality was related to overweight and obesity in only 5 mandatory.

\begin{tabular}{|l|c|c|c|c|c|}
\hline \multicolumn{7}{|c|}{} & Cidade & $\mathbf{N}$ & Mean & $\begin{array}{c}\text { Std. } \\
\text { Deviation }\end{array}$ & $\begin{array}{c}\text { Std. Error } \\
\text { Mean }\end{array}$ \\
\hline \multirow{2}{*}{ idade } & 1 & 90 & 3,57 & 1,142 &, 120 \\
\cline { 2 - 6 } & 2 & 89 & 2,79 & 1,344 &, 142 \\
\hline $\begin{array}{l}\text { zBMI BMI-for- } \\
\text { age z-score }\end{array}$ & 1 & 87 &, 3840 & 1,23231 &, 13212 \\
\cline { 2 - 6 } $\begin{array}{l}\text { zhaz Length/ } \\
\text { height-for-age } \\
\text { z-score }\end{array}$ & 2 & 89 &, 4065 & 1,32624 &, 14058 \\
\cline { 2 - 6 } & 2 & 80 &,- 5007 & 1,46492 &, 15442 \\
\hline $\begin{array}{l}\text { zwaz } \\
\text { Weight-for-age } \\
\text { z-score }\end{array}$ & 2 & 89 &, 5009 & 1,22696 &, 13006 \\
\cline { 2 - 6 } & 1 & 89 &,- 0583 & 1,04065 &, 11031 \\
\hline
\end{tabular}

Table 1

As for the quality of sleep analyzed by the Pittsburg questionnaire (PSQI-BR), there was a result obtained regarding disturbances during sleep, $14.4 \%$ in Porto Alegre and 18\% in Frederico Westphalen, there was also a significant difference in terms of time the 
children took to sleep, 34.4\% in Porto Alegre and 16.9\% in Frederico Westphalen (Table 2).

\begin{tabular}{|c|c|c|c|c|}
\hline \multicolumn{5}{|c|}{ Ranks } \\
\hline & Cidade & $\mathbf{N}$ & $\begin{array}{l}\text { Mean } \\
\text { Rank }\end{array}$ & $\begin{array}{l}\text { Sum of } \\
\text { Ranks }\end{array}$ \\
\hline \multirow[t]{3}{*}{ PL } & 1 & 90 & 102,19 & 9197,00 \\
\hline & 2 & 89 & 77,67 & 6913,00 \\
\hline & Total & 179 & & \\
\hline \multirow[t]{3}{*}{$\mathrm{COP}$} & 1 & 90 & 95,36 & 8582,50 \\
\hline & 2 & 89 & 84,58 & 7527,50 \\
\hline & Total & 179 & & \\
\hline \multirow[t]{3}{*}{ OG } & 1 & 90 & 87,58 & 7882,50 \\
\hline & 2 & 89 & 92,44 & 8227,50 \\
\hline & Total & 179 & & \\
\hline \multirow[t]{3}{*}{ GP } & 1 & 90 & 96,57 & 8691,50 \\
\hline & 2 & 89 & 83,35 & 7418,50 \\
\hline & Total & 179 & & \\
\hline \multirow[t]{3}{*}{$\mathrm{HL}$} & 1 & 90 & 74,59 & 6713,50 \\
\hline & 2 & 89 & 105,58 & 9396,50 \\
\hline & Total & 179 & & \\
\hline \multirow[t]{3}{*}{ FR } & 1 & 90 & 79,47 & 7152,50 \\
\hline & 2 & 89 & 100,65 & 8957,50 \\
\hline & Total & 179 & & \\
\hline \multirow[t]{3}{*}{ Diver } & 1 & 90 & 88,54 & 7968,50 \\
\hline & 2 & 89 & 91,48 & 8141,50 \\
\hline & Total & 179 & & \\
\hline \multirow[t]{3}{*}{ PSQ6 C1-QUALIDADE } & 1 & 90 & 92,74 & 8347,00 \\
\hline & 2 & 89 & 87,22 & 7763,00 \\
\hline & Total & 179 & & \\
\hline \multirow[t]{3}{*}{ PSQC2 C2-LATENCIA } & 1 & 90 & 97,97 & 8817,00 \\
\hline & 2 & 89 & 81,94 & 7293,00 \\
\hline & Total & 179 & & \\
\hline \multirow[t]{3}{*}{ PSQC3 C3-DURAÇÃO } & 1 & 90 & 90,46 & 8141,50 \\
\hline & 2 & 89 & 89,53 & 7968,50 \\
\hline & Total & 179 & & \\
\hline \multirow[t]{3}{*}{ PSQC4 C4-EFICIENCIA } & 1 & 90 & 89,32 & 8038,50 \\
\hline & 2 & 89 & 90,69 & 8071,50 \\
\hline & Total & 179 & & \\
\hline \multirow{3}{*}{$\begin{array}{c}\text { PSQC5 C5-DISTUR- } \\
\text { BIOS }\end{array}$} & 1 & 90 & 87,63 & 7886,50 \\
\hline & 2 & 89 & 92,40 & 8223,50 \\
\hline & Total & 179 & & \\
\hline
\end{tabular}

\begin{tabular}{|c|c|c|c|c|}
\hline \multirow{3}{*}{$\begin{array}{c}\text { PSQ7 C6-MEDICAÇÃO } \\
\text { SONO }\end{array}$} & 1 & 90 & 89,99 & 8099,00 \\
\cline { 2 - 5 } & 2 & 89 & 90,01 & 8011,00 \\
\cline { 2 - 5 } & Total & 179 & & \\
\hline $\begin{array}{c}\text { PSQ8 C7-SONOLENCIA } \\
\text { DIURNA }\end{array}$ & 1 & 90 & 91,08 & 8197,00 \\
\cline { 2 - 5 } & 2 & 89 & 88,91 & 7913,00 \\
\cline { 2 - 5 } & Total & 179 & & \\
\hline
\end{tabular}

Table 2

Regarding eating habits, there was a relationship with the quality of sleep and the consumption of dairy products (more than 8 times a day). There was an average of 5 meals a day.

It turns out that children in Porto Alegre had a higher rate of overweight and obesity and also, a rate means sleep disorders and delayed sleep, which may suggest that children who have poorer quality sleep are associated with being overweight.

In the present study, it was found that $70 \%$ of the sample was overweight and obese, and that the average number of hours of sleep per day was 9.4 hours, with the majority having a quality of sleep considered to be good, however it is suggested that the number of hours is still insufficient for the population studied.

Jong., et al. (2012) [14], in his study, used variables such as watching television and standing in front of the computer to study the relationship between sleep duration $x$ childhood obesity. 4,072 children aged 4 to 13 years were evaluated, and it was found that there is a relationship between shorter sleep duration and excess weight, and among the determinants of sleep duration were watching television during the meal, permission to having sweets without asking, and sleeping late, being stronger the association with watching television and using the computer.

In recent years, several lines of research have been developed that have deepened the understanding of the mechanisms regulating energy balance, the genetic basis that occurs or not the pathological accumulation of adipose tissue, as well as in the analysis of function, or endocrine dysfunction, of them [6].

Overweight and obesity among children and adolescents are probably the result of complex interactions between genes, lifestyle behaviors, eating habits and socioeconomic factors [15]. Among several risk factors already mentioned for obesity, attention has now been paid to inadequate and poor quality sleep in children and adolescents [7], and this habit can be a risk factor. 
The reduction in sleep duration has been associated with the development of cardiovascular diseases in adults, however the effects of a reduction in sleep duration on heart health in children are still poorly understood [16].

According to studies, children up to 6 years of age who have short sleep during childhood (sleeping $<10 \mathrm{~h} /$ night), have a higher risk of developing overweight or obesity compared to children who sleep $\geq 11 \mathrm{~h} /$ night [8], confirming data of the present study.

Another study, with a similar age group, carried out with 915 children aged 3 years or less found that sleep less than 12 hours is associated with a higher body mass index (BMI), thus the duration of daily sleep less than 12 hours in preschool children seems to be a risk factor for overweight and obesity [17].

Von Kries., et al. (2002) [18], evaluated the relationship between sleep duration and adiposity in children aged 5 to 6 years in the region of Bavaria (Germany). A total of 6,862 children participated in the study. The prevalence of obesity decreased with increasing sleep duration. The authors concluded that sleep duration correlated with obesity in children, which appears to be independent of other risk factors for obesity.

Meng., et al. (2012) [7] carried out a study with 6,576 schoolaged children from urban areas of China, where the body mass index (BMI), body fat percentage and sleep habits were compared. It was found that the average sleep duration was 9.7 hours with a decreasing trend over the years, with children who slept less than 9 hours a night at a higher risk of overweight, obesity and abdominal obesity, and that the duration of sleep was negatively associated with BMI, however there was no relationship between sleep duration and body fat.

Archbold., et al. (2012) [16] carried out a study with 334 children, following them for a period of 5 years. The author found that the average hours of sleep was 8 hours, decreasing to 7 hours at the end of 5 years, and there was also a relationship between the increase in BMI and reduction in hours of sleep, however the most significant result was the relationship between o sleep less and increase levels of systolic blood pressure and diastolic blood pressure.

Chaput, Brunet and Tremblay (2006) [19] analyzed 422 schoolaged children and found overweight and obesity of $20 \%$ and $24 \%$ in boys and girls, respectively. The authors found that there was a relationship between poor sleep and overweight and obesity in children, with children with $12-13 \mathrm{~h}$ of sleep as a reference, the odds ratio was 1.42 for those with 10.5-11, 5 h of sleep and 3.45 for those with 8-10 h of sleep.

The data found in the present study confirmed what was previously mentioned and in other studies [15,20]. However, the average age of the children surveyed is lower than the average age of most studies, so more research is needed for a more accurate comparison. Studies also show that sleep brings endocrine and metabolic changes [8]. Leptin and ghrelin are hormones that contribute to the regulation of the central intake. Leptin, a hormone released by adipocytes, provides information on the amount of energy and regulates the hypothalamus [21,22], is released during sleep and has the function of preventing sleep disturbance by the root of hunger [23]. Ghrelin, on the other hand, escapes in the stomach, stimulates appetite and gastric emptying, its levels tend to rise with fasting and during sleep [24].

Studies show adults in a sleep restriction have a decrease in leptin levels and an increase in ghrelin levels [25,26].

However, in this study there was no dosage of these hormones due to the high custom of the exam and, also, to the age of the children, limiting the study, due to a survey to parents about whether they would authorize invasive exams in their children.

A study in adults, that eating habits were different between those who sleep little and those who sleep a long sleep, such fed a nutritionally poor diet, with greater consumption of sweets and less intake of fruits and vegetables [27].

Another study found that shorter sleep duration ( $<8$ hours/ day) was associated with a relative increase in fat-derived caloric intake and a decrease in carbohydrate calorie intake, and was also associated with a probability 2, 1 times higher per day of consumption 475 or more kcal of snacks [10].

There are surveys that sleep restriction contributes to peripheral insulin sensitivity in adults with Type 1 Diabetes Melitus. Studies also show that healthy adults and adolescents have their glucose metabolism altered when they have poor quality sleep [9]. 
A systematic review and meta-analysis of 10 studies in adults, a consistent and unambiguous pattern of an increased risk for developing type 2 diabetes at both ends of the sleep duration distribution and with qualitative sleep disorders. The risk varies between $28 \%$ in people who reported normal sleep of less than 5-6 h/night and $84 \%$ in those with difficulties in maintaining sleep.

In this study, there was no assessment of children's blood glucose due to the difficulty of parents' acceptance of adherence to this type of research.

\section{Conclusion}

In this study there was no relationship between eating habits and quality of sleep, however there is still a great lack of research on the subject, making it a limitation for comparing results, most studies are children over the age of six teenagers.

The study had two points of limitations. The first, that the Food Frequency Questionnaire (FFQ) has been the method most commonly used in epidemiological studies due to its reliability and relative validity, practicality and speed of application and low cost, however there may have been a bias in the participants when reporting higher consumption of more socially accepted foods and less consumption for less socially accepted foods, another reason would be the difficulty of those responsible for the individuals studied in remembering the foods consumed and the portion sizes, considering that the children stay full time in school and eat at least 4 meals in the period, as reported in other studies. The second is about the non-dosage of the hormones leptin and ghrelin, and also of glucose, because such tests become too expensive for researchers to pay for, requiring the help of some guarantor organ, and also due to the difficulty in authorizing parents to collect them the blood sample for the exam.

Finally, it is concluded that in the study there was a relationship between the hours of sleep and the rate of overweight and obesity in the sample, however there was no relationship between eating habits and sleep duration.

\section{Acknowledgements}

Nothing to declare.

\section{Conflict of Interest}

Nothing to declare.

\section{Bibliography}

1. Adair L. "Child and adolescent obesity: Epidemiology and development perspectives". Physiology and Behavior 94 (2008): 8-16.

2. Padez C., et al. "Prevalence of Overweight and Obesity in 7-9-year-old Portuguese children: trends in body mass índex from 1970-2002". American Journal of Human Biology 16 (2004): 670-678.

3. Taheri S. "The link between short sleep duration and obesity: we should recommend more sleep to prevent obesity". Archives of Disease in Childhood 91.16 (2006): 881-884.

4. Birch LL and Ventura AK. "Preventing childhood obesity: what works?" International Journal of Obesity (Lond) 33 (2009): S74-81.

5. Centers for Disease Control and Prevention (CDC). "Unhealthy sleep-related behaviors - 12 States, 2009”. MMWR Morbidity and Mortality Weekly Report 60.8 (2011): 233-238.

6. Chen X., et al. "Is sleep duration associated with childhood obesity? A systematic review and meta-analysis". Obesity (Silver Spring) 16.2 (2008): 265-274.

7. Beccuti G and Pannain S. "Sleep and obesity". Current Opinion in Clinical Nutrition and Metabolic Care 14.4 (2011): 402-412.

8. SOCIEDADE BRASILEIRA DE PEDIATRIA. "Obesidade na infância e adolescência - Manual de Orientação”. Departamento Científico de Nutrologia. 2ª Ed. São Paulo: SBP (2012).

9. Leal Vanessa Sá., et al. "Excesso de peso em crianças e adolescentes no Estado de Pernambuco, Brasil: prevalência e determinantes". Cad. Saúde Pública. Rio de Janeiro 28.6 (2012): 1175-1182.

10. Cauter Eve Van and Knutson Kristen. "Sleep and the epidemic of obesity in children and adults". European Journal of Endocrinology 159.1 (2008): 59-66.

11. Rocha DS., et al. "Estado nutricional e prevalência de anemia em crianças que freqüentam creches em Belo Horizonte, Minas Gerais". Revista Paulista de Pediatria 36.1 (2008): 6-13.

12. Touchette E., et al. "Associations between sleep duration pat?terns and overweight/obesity at age 6". Sleep 31.11 (2008): 1507-1514. 
13. Stamatakis Katherine A and PunjabiI Naresh. "Effects of Sleep Fragmentation on Glucose Metabolism in Normal Subjects". Chest 137.1 (2010) 95-101.

14. Gangwisch, James E., et al. "Inadequate Sleep as a Risk Factor for Obesity: Analyses of the NHANES I". Sleep 28.10 (2005).

15. Buyse DJ., et al. "The Pittsburg Sleep Quality Index: a new instrument for psychiatric practice and research". Psychiatry Review 28 (1989): 193-213.

16. World Health Organization. WHO - Growth reference data for 5-19 years (2007).

17. World Health Organization. WHO - Growth reference data for 5-19 years (2010).

18. Ministério da Saúde, Secretaria de Atenção à Saúde, Departamento de Atenção Básica, Coordenação-Geral da Política de Alimentação e Nutrição. Incorporação das curvas de crescimento da Organização Mundial da Saúde de (2006).

19. Silva GAP., et al. "Prevalência de sobrepeso e obesidade em crianças pré-escolares matriculadas em duas escolas particulares de Recife, Pernambuco". Revista Brasileira de Saúde Materno Infantil 3.3 (2003): 323-327.

20. Simon VGN., et al. "Prevalência de sobrepeso e obesidade em crianças de dois a seis anos matriculadas em escolas particulares no município de São Paulo". Journal of Human Growth and Development 19.2 (2009): 211-218.

21. Fundação Nacional do Sono EUA - National Sleep Foundation's sleep time duration recommendations (2015).

22. EM Taveras., et al. "Chronic Sleep Curtailment and Adiposity". Pediatrics 133.6 (2014): 1013.

23. Spielgel Karine., et al. "Leptin Levels Are Dependent on Sleep Duration: Relationships with Sympathovagal Balance, Carbohydrate Regulation, Cortisol, and Thyrotropin". The Journal of Clinical Endocrinology and Metabolism 89.11 (2004): 57625771.

24. American Heart Association (2015).

25. BARUKI SBS., et al. "Associação entre estado nutricional e atividade física em escolares da Rede Municipal de Ensino de Corumbá - MS". Revista Brasileira de Medicina Esportiva 12.2 (2006): 90-94.

26. Bender Silvia Cercal. "Influencia dos fatores ambientais na obesidade infantile”. Trabalho Final de Graduação apresen- tado ao Curso de Nutrição - Área de Ciências da Saúde,do Centro Universitário Franciscano, como requisito parcial para obtenção do grau de Nutricionista - Bacharel em Nutrição de (2006).

27. Hulley SB., et al. "Delineando a pesquisa clínica: uma abordagem epidemiológica”. 3a edição, Porto Alegre: Artmed (2008): 384.

Volume 5 Issue 11 November 2021

CAll rights are reserved by Haider JCMC., et al. 